\title{
8-2013
}

\section{Review of Concussion and Return-to-Play Guidelines in Sport}

\author{
Michael J. Lang, MD \\ Thomas Jefferson University \\ Ameet Chitale \\ Thomas Jefferson University \\ Kevin D. Judy, MD \\ Thomas Jefferson University
}

Follow this and additional works at: https://jdc.jefferson.edu/jhnj

\section{Let us know how access to this document benefits you}

\section{Recommended Citation}

Lang, MD, Michael J.; Chitale, Ameet; and Judy, MD, Kevin D. (2013) "Review of Concussion and Return-toPlay Guidelines in Sport," JHN Journal: Vol. 8 : Iss. 1 , Article 1.

DOI: https://doi.org/10.29046/JHNJ.008.1.001

Available at: https://jdc.jefferson.edu/jhnj/vol8/iss1/1

This Article is brought to you for free and open access by the Jefferson Digital Commons. The Jefferson Digital Commons is a service of Thomas Jefferson University's Center for Teaching and Learning (CTL). The Commons is a showcase for Jefferson books and journals, peer-reviewed scholarly publications, unique historical collections from the University archives, and teaching tools. The Jefferson Digital Commons allows researchers and interested readers anywhere in the world to learn about and keep up to date with Jefferson scholarship. This article has been accepted for inclusion in JHN Journal by an authorized administrator of the Jefferson Digital Commons. For more information, please contact: JeffersonDigitalCommons@jefferson.edu. 


\section{Review of Concussion and Return-to-Play Guidelines in Sport}

\author{
Michael J. Lang, MD; Ameet V. Chitale, MD; Kevin D. Judy, MD \\ Department of Neurosurgery, Thomas Jefferson University and Jefferson Hospital for Neuroscience, \\ Philadelphia, Pennsylvania, USA
}

\section{INTRODUCTION}

Concussion is a form of mild traumatic head injury (TBI) associated with a variety of neurologic signs and symptoms. While historically trivialized in its significance, significant progress has been made in the medical literature and lay understanding of concussion. Severe TBI, long the subject of extensive research, has come under increased scrutiny following experience with blast injuries during the wars in Afghanistan and Iraq. Such experience, grievously earned, has brought significant public attention and funding to the study of head injury. However, for the civilian population, concussion continues to be the most common form of traumatic brain injury, and athletics continues to be the single largest cause of concussion.

Concussion in sports has come under substantial scrutiny as a result of widely publicized injuries in major American sports, particularly football and hockey. Media coverage has increased further as understanding of the related yet distinct syndrome of chronic traumatic encephalopathy (CTE), formerly known as dementia pugilistica or "punch-drunk syndrome", and its proposed mechanism of repeated sub-concussive trauma has increased. While media attention has focused primarily on concussion in professional athletes, the majority of sports-related concussions occur in youth participants. ${ }^{1}$ With relative unavailability of physicians trained in on-field assessment of concussed athletes relative to professional sports teams, youth athletes are at significant risk for short- and long-term neurologic injury from concussion. This manuscript aims to outline the natural history of sports concussion and review recent updates in on-field assessment and return-to-play guidelines.

\section{EPIDEMIOLOGY AND NATURAL HISTORY OF CONCUSSION}

There are a reported 1.6 to 3.8 million sports-related concussions every year in the United States. ${ }^{2}$ These data are believed to be a conservative estimate of the true annual incidence of concussions for several reasons. Event under-reporting can occur when players themselves fail to disclose an injury to prevent removal from competition. Lack of agreement or understanding by medical or athletic training staff as to what constitutes a concussion is a significant source of unreported and untreated injury. ${ }^{3}$

In order to clarify the assessment and management of concussion, a series of position papers from the International Conference on Concussion in Sport have been published. ${ }^{4-6}$ The most recent, the 4th International Conference on Concussion in Sport, held in Zurich in November of $2012,{ }^{7}$ has sought to further refine definitions and management decisions in concussion. The paper defines concussion as such:

Concussion is a brain injury and is defined as a complex pathophysiological process affecting the brain, induced by biomechanical forces. Several common features that incorporate clinical, pathologic and biomechanical injury constructs that may be utilized in defining the nature of a concussive head injury include:

1. Concussion may be caused either by a direct blow to the head, face, neck or elsewhere on the body with an 'impulsive' force transmitted to the head.

2. Concussion typically results in the rapid onset of short-lived impairment of neurological function that resolves spontaneously. However, in some cases, symptoms and signs may evolve over a number of minutes to hours.
3. Concussion may result in neuropathological changes, but the acute clinical symptoms largely reflect a functional disturbance rather than a structural injury and, as such, no abnormality is seen on standard structural neuroimaging studies.

4. Concussion results in a graded set of clinical symptoms that may or may not involve loss of consciousness. Resolution of the clinical and cognitive symptoms typically follows a sequential course. However, it is important to note that in some cases symptoms may be prolonged.

The authors acknowledge that the science of concussion is actively evolving, and as a result place impetus on the diagnosing physician to assess and manage concussed patients on an individualized basis.

Concussion encompasses a broad array of neurologic symptoms, with wide ranges of duration and frequency after the initial trauma. Brief loss of consciousness, long considered the hallmark of concussion by older definitions, occurs in only a small percentage of patients. ${ }^{8,9}$ In a study of 1015 Australian Rules Football players over 4 years (at the elite, juniors, and recreational levels of play), of 88 concussions observed in 78 players, only 32 (36.4\%) resulted in loss of consciousness. ${ }^{1}$ More commonly observed were headache, confusion/disorientation, visual disturbance, fatigue/lethargy, dizziness, amnesia (typically retrograde), sleep disturbance, and imbalance. These symptoms may be present immediately after ictus or may evolve over time. Of these, headache and sleep disturbance were of the longest duration, returning to normal up to 10 days later, though most players reported complete resolution of symptoms by 5-7 days following ictus.

Also noted in the study by Makdissi et al. was the independence of resolution of neurological symptoms and cognitive dysfunction in the concussed athlete. ${ }^{1}$ Based on a computerized battery of cognitive tests (discussed below), the authors noted that cognitive dysfunction, particularly delayed processing speed, 
recovered 2 to 3 days following the resolution of reported symptoms. It is important to note, however, that the sensitivity of such cognitive testing is greatly reduced when athletes are compared to normative population-based standards, as opposed to individual pre-injury baseline tests. ${ }^{10}$

Late effects of concussive injury include predisposition to repeat injury as well as long-term persistent symptoms. In a prospective study of NCAA football players, there was a threefold increase in concussion incidence in players with a prior history of 3 or more concussions. ${ }^{11}$ In those studied athletes experiencing a repeat concussion within the study period, $75.0 \%$ and $91.7 \%$ occurred within 7 and 10 days of the previous concussion, respectively. Additionally, there was a correlation between a history of multiple previous concussions and delayed resolution of symptoms, with $30.0 \%$ of players with 3 or more concussions reporting symptoms persisting longer than one week as compared to $14.6 \%$ in those without prior history of concussion.

Second impact syndrome is a particularly feared complication of repeat concussion, particularly in the pediatric population, first described by Saunders and Harbaugh in $1984 . .^{12,13}$ While the existence and pathophysiology of this condition is still under some debate, it is postulated that even mild traumatic brain injury can result in disruption of normal autoregulation of cerebral perfusion as well as decoupling of flow and glucose metabolism. ${ }^{14} \mathrm{~A}$ second concussive event closely following the first can result in rapid onset of malignant cerebral edema and often death. It is for this reason, as well as the subtlety and increased persistence of cognitive changes compared to affected adults, that management of concussion in children is significantly more conservative.

Long-term effects of concussion include depression and other psychiatric disturbance, as well as an array of neurodegenerative changes. Repeat concussions have been identified as a risk factor in clinical depression..${ }^{15}$ In a retrospective study of 2500 retired National Football League players, a dose-dependent association between concussion and depression was found, with an overall $11.1 \%$ prevalence in the cohort, but with a $150 \%$ increased incidence in those with 2 diagnosed concussions and a $300 \%$ increase in those with 3 or more. ${ }^{16}$ Similarly, the still-evolving knowledge of the condition termed CTE is felt to occur in a dose-dependent manner as well. ${ }^{17}$ The prevalence of this condition is as yet not elucidated, as CTE can only be definitively diagnosed post-mortem. Chronic traumatic encephalopathy is a tauopathy with neurodegenerative changes with features of Alzheimer's disease and Parkinson's disease, as well as severe psychological deterioration including increased suicidal ideation. ${ }^{18}$ The suicides of several former NFL players subsequently diagnosed with CTE have done much to generate public concern for the long-term consequences of concussion and sub-concussive mild traumatic brain injury. However, it is important to note, however that as yet a cause-effect relationship between CTE and head injury has not been definitively established.

\section{ON-FIELD ASSESSMENT AND RETURN-TO-PLAY GUIDELINES}

The recently published 2012 Zurich Consensus Statement includes specific recommendations regarding on-field assessment and returnto-play guidelines. ${ }^{7}$ Any player suspected of having sustained a concussion should be evaluated immediately by a physician trained in diagnosis of concussion. Immediate attention should be paid to standard emergency assessment, with particular concern for co-existent cervical spine injury. A player with suspected concussion (i.e. with any signs or symptoms of concussion or cognitive/psychological changes) should immediately be removed from play and assessed, ideally in a quiet, off-site environment. A standardized assessment of neurologic function should then be performed to aid in diagnosis of concussion.

The 2012 Zurich Consensus recommends the use of the Sports Concussion Assessment Tool, 3rd edition (SCAT3) for assessment of the concussed patient. ${ }^{19}$ This standardized assessment includes GCS score as well as Maddocks score, utilized due to the insensitivity of standard orientation questions following concussion. ${ }^{20}$ A symptom questionnaire with scaled severity and cognitive assessment including delayed recall and concentration tasks are performed. Finally, balance and coordination are tested. Recent evidence suggests that balance disturbance results from visual-motor dysintegration following concussive injury. Moreover, there appears to be differential recovery between imbalance and the typical post-concussive symptoms and cognitive changes. Indeed, Slobounov et al. demonstrated persistence of induced imbalance up to 30 days following concussion in collegiate athletes. ${ }^{21}$ In this cohort, all patients reported complete resolution of symptoms within 10 days of injury, but imbalance, as evidenced by incoherence with visual field motion postural changes, persisted up to 30 days. Furthermore, there was a dose-dependent increase in delayed resolution of imbalance for those with previously reported concussions. Any player with diagnosed concussion should not be allowed to return to play the day of injury.

The Zurich Consensus has also supported a graduated recovery paradigm following concussion (Figure 1). Each of 6 stages of recovery should take roughly 24 hours, such that full recovery is roughly one week following injury. The first day following injury should be restricted to physical and cognitive rest. The subsequent days should include progressive increases in physical activity and sport-specific cognitive demands. This includes transition through light aerobic activity, sport-specific movement drills, complex non-contact team training drills, and full contact practice prior to resumption of full competitive play. If symptoms return at any point in this progression, the athlete should return to the previous stage until postconcussive symptoms resolve. These return to play guidelines can be lengthened if any concussion modifiers are present, including prolonged loss of consciousness, concussive convulsions, repeated concussions (especially with progressively lower impact thresholds), or with children and adolescents.

In addition, during the recovery phase it is recommended that players undergo neuropsychological testing. Various forms of such testing exist, and it has been found that computerized testing offers a cost-effective, low labor-intensive regimen with the added benefit of easily performed timing of cognitive response assays. One of the most studied of these, the Immediate Post-Concussion Assessment and Cognitive Testing (ImPACT) has been validated as a sensitive measure of persistent concussive symptoms when combined with post-concussion symptom scores as compared to symptom scores 
Table 1. Graduated Return-to-Play Protocol (McCrory et al., 2013)

\begin{tabular}{|c|c|c|}
\hline Rehabilitation Stage & Functional Exercise & Objective \\
\hline \multicolumn{3}{|l|}{ Idiopathic } \\
\hline 1. No Activity & Complete physical \& cognitive rest & Rest \\
\hline 2. Light Aerobic Exercise & $\begin{array}{l}\text { Walking, swimming, stationary cycling, }<70 \% \text { max heart } \\
\text { rate, no resistance training }\end{array}$ & Increase heart rate \\
\hline 3. Sport-Specific Exercise & Running/skating drills. No head impact & Add Movement \\
\hline 4. Non-Contact Training Drills & $\begin{array}{l}\text { Complex training drills, (e.g. passing drills in football/ } \\
\text { hockey), may add progressive resistance training }\end{array}$ & Exercise, coordination, cognitive load \\
\hline 5. Full-Contact Practice & Full practice following medical clearance & $\begin{array}{l}\text { Restore confidence, assess functional skill } \\
\text { by coaching staff }\end{array}$ \\
\hline 6. Return to Play & Normal game play & \\
\hline
\end{tabular}

alone. ${ }^{10}$ As stated previously, it should be noted that these data only apply when athletes are tested against their own established baseline testing. ${ }^{22}$. Furthermore, in cases of persistently delayed recovery of cognitive function, formal neuropsychological testing should be performed.

At this time, while there is evidence to support identifiable post-concussive changes in functional magnetic resonance imaging (fMRI), electroencephalography (EEG), and other adjunct tests, their widespread use has not yet been supported. ${ }^{23,24}$

\section{CONCLUSION}

Concussion is a common form of injury among athletes. It can present with an array of neurologic and cognitive deficits, which may be present initially or evolve over time. An athlete with a suspected concussion should be removed immediately from play and assessed by a trained physician. Recovery should be performed with stepwise progression toward full contact play, with delayed return-to-play and additional testing should symptoms persist, and resolution of balance and cognitive changes may outlast classically defined post-concussive symptoms.

\section{REFERENCES}

1. Makdissi, M., et al., Natural History of Concussion in Sport: Markers of Severity and Implications for Management. The American Journal of Sports Medicine, 2010. 38(3): p. 464-471.
2. Langlois, J.A., W. Rutland-Brown, and M.M. Wald, The epidemiology and impact of traumatic brain injury: a brief overview. J Head Trauma Rehabil., 2006. 21(5): p. 375-8

3. Guskiewicz, K.M., et al., National Athletic Trainers' Association Position Statement: Management of Sport-Related Concussion. J Athl Train., 2004. 39(3): p. 280-297.

4. Aubry, M., et al., Summary and agreement statement of the 1st International Symposium on Concussion in Sport, Vienna 2001. Clin J Sport Med., 2002. 12(1): p. 6-11.

5. McCrory, P., et al., Summary and agreement statement of the 2nd International Conference on Concussion in Sport, Prague 2004. Br J Sports Med., 2005. 39(4): p. 196-204.

6. McCrory, P., et al., Consensus statement on concussion in sport - the Third International Conference on Concussion in Sport held in Zurich, November 2008. Phys Sportsmed., 2009. 37(2): p. 141-59. doi: 10.3810/psm.2009.06.1721.

7. McCrory, P., et al., Consensus statement on concussion in sport: the 4th International Conference on Concussion in Sport held in Zurich, November 2012 Br J Sports Med., 2013. 47(5): p. 250-8. doi: 10.1136/ bjsports-2013-092313.

8. Erlanger, D., et al., Symptom-based assessment of the severity of a concussion. J Neurosurg., 2003. 98(3): p. 477-84.

9. McCrory, P.R., T. Ariens, and S.F. Berkovic, The nature and duration of acute concussive symptoms in Australian football. Clin J Sport Med., 2000. 10(4): p. 235-8.

10. Broglio, S.P., S.N. Macciocchi, and M.S. Ferrara, Sensitivity of the Concussion Assessment Battery. Neurosurgery, 2007. 60(6): p. 1050-1058.

11. Guskiewicz, K.M., et al., Cumulative effects associated with recurrent concussion in collegiate football players: the NCAA Concussion Study. Jama., 2003. 290(19): p. 2549-55.

12. Cantu, R.C., Second-impact syndrome. Clin Sports Med., 1998. 17(1): p. 37-44.
13. Saunders, R.L. and R.E. Harbaugh, The second impact in catastrophic contact-sports head trauma. Jama., 1984. 252(4): p. 538-9.

14. Wetjen, N.M., M.A. Pichelmann, and J.L. Atkinson, Second impact syndrome: concussion and second injury brain complications. J Am Coll Surg., 2010. 211(4): p. 553-7. doi: 10.1016/j.jamcollsurg.2010.05.020. Epub 2010 Jul 14.

15. Holsinger, T., et al., Head injury in early adulthood and the lifetime risk of depression. Arch Gen Psychiatry., 2002. 59(1): p. 17-22.

16. Guskiewicz, K.M., et al., Recurrent concussion and risk of depression in retired professional football players. Med Sci Sports Exerc., 2007. 39(6): p. 903-9.

17. Omalu, B.I., et al., Chronic traumatic encephalopathy, suicides and parasuicides in professional American athletes: the role of the forensic pathologist. Am J Forensic Med Pathol., 2010. 31(2): p. 130-2. doi: 10.1097/PAF.0b013e3181ca7f35.

18. McKee, A.C., et al., Chronic traumatic encephalopathy in athletes: progressive tauopathy after repetitive head injury. J Neuropathol Exp Neurol., 2009. 68(7): p. 709-35. doi: 10.1097/NEN.0b013e3181a9d503.

19. SCAT3. Br J Sports Med., 2013. 47(5): p. 259.

20. Maddocks, D.L., G.D. Dicker, and M.M. Saling, The assessment of orientation following concussion in athletes. Clin J Sport Med., 1995. 5(1): p. 32-5.

21. Slobounov, S., et al., Differential Rate of Recovery in Athletes after First and Second Concussion Episodes. Neurosurgery, 2007. 61(2): p. 338-344.

22. Covassin, T., et al., Immediate post-concussion assessment and cognitive testing (ImPACT) practices of sports medicine professionals. J Athl Train., 2009. 44(6): p. 639-44. doi: 10.4085/1062-6050-44.6.639.

23. Gosselin, N., et al., Brain functions after sportsrelated concussion: insights from event-related potentials and functional MRI. Phys Sportsmed., 2010. 38(3): p. 27-37. doi: 10.3810/psm.2010.10.1805

24. McCrea, M., et al., Acute effects and recovery after sport-related concussion: a neurocognitive and quantitative brain electrical activity study. J Head Trauma Rehabil., 2010. 25(4): p. 283-92. doi: 10.1097/HTR.0b013e3181e67923. 